\title{
GAME-BASED TRAINING: AN EFFECTIVE METHOD FOR REDUCING BEHAVIORAL-FINANCE BIASES
}

\author{
Francesco Tommasi, Andrea Ceschi, Marija Gostimir, Marco Perini, \& Riccardo Sartori \\ Department of Human Sciences, University of Verona (Italy)
}

\begin{abstract}
Nowadays, being able to understand and infer reasonable conclusions based on great amounts of numerical information represents a key competence to succeed both in education and work. Numeracy is defined as the ability to understand, think, and reason using numbers and math concepts. Such a competence is key in the field of behavioral-finance where individuals manage numerical information to face important choices. Indeed, numeracy is fundamental to analyze data and to make predictions on the likelihood of future events. Moreover, research shows that individuals who score high on numeracy report higher ability in creating alternative options when it turns to make decisions. Building on the computer-supported collaborative learning and on the technology acceptance model, this study aimed to evaluate the efficacy of different interventions to reduce psychological biases related to numerical information processes in a group of university students $(\mathrm{N}=800)$. Specifically, we devised two training interventions based on the two educational approaches, i.e., the computer-supported collaborative learning and on the technology acceptance model. Participants were randomly assigned to one of the two conditions, and -post measures were collected after the interventions to assess their numerical information processing ability. Moreover, post-training results were compared with the results of a control group. Results of a one-way ANOVA showed that in the control group reported the highest incidence of numeracy biases. Our preliminary findings support the main literature on the use of technological instruments and distant training as keys to develop cognitive and operational competences. Such results are limited since we were unable to collect -pre-measures of participants' numeracy biases. Overall, the present contribution provides initial insights into how different kind of technology-based trainings can be effective to reduce biases referred to numerical information processing.
\end{abstract}

Keywords: E-learning, distant training, cognitive biases, numeracy, decision-making.

\section{Introduction}

By the recent labor economic transformation, being able to understand and infer reasonable conclusions based on great amounts of numerical information represents a key competence to succeed both in education (Lusardi \& Mitchell, 2014) and work (Tommasi, Franceschinis, Perini and Sartori, 2020). Nowadays, the increase in numerical data charges led to consider how individuals process information and make informed decisions (Waeneryd, 2001; Lusardi, 2015; Lusardi and Mitchell 2014). Evidence attesting the inadequacy of rational models to explain individual decision-making made the basis for insights into the area of Behavioral-Finance Biases (DeLong and Magin, 2009; Thaler, 1985). For example, literature shows the incidence of numeracy as a core aspect to be considered when making decisions in this domain. Such mental errors occur when individuals do not consider numerical information or are not able to understand numerical data, preferring different evaluation objects (Rieger, 2012; Fox and Tversky, 1995). Personal interests and preferences, mental representations, or anchoring on specific information are cases of cognitive biases which compromise the effect of individuals' decision-making process. Indeed, individuals show inadequate models in making reasonable decisions during economical financial deals (Rieger, 2012; Shefrin and Thaler, 1992; Thaler, 1985, Waeneryd, 2001). For instance, a low level of low level of numeracy is seen in the application of wrong mental calculations which violate economical and mathematical calculations. Alternatively, else, individuals avoid risks when information is ambiguous or prefer mental and personal representations of the information rather than the numerical and economical values. Cognitive errors are caused by fewer levels of numeracy, which cover both the knowledge and the abilities needed to understand, think, and reason using numbers and math concepts (Lusardi and Mitchell, 2014; MacGregor, Slovic, Dreman and Berry, 
2000; Olsen and Cox, 2001; Shapira, 1995). The growing financialization and the rise of financial complexity, training interventions for helping individuals to reduce the cognitive biases' incidence are largely recommended. Hence, in the area of possible interventions for improving and developing individuals' skills, remedial training methods for reducing behavioral-finance biases are offered by the technological progress. Over the years, authors proposed technological methods suggesting that didactic instruments for distance training and real-life simulations are effective tools for helping individuals learning (Dal Santo and Martelli, 2015; Król and Król, 2019; Willis, 2011) which are rooted into different educational approaches, i.e., the computer supported collaborative learning and the technology acceptance model (Król and Król, 2019). While e-learning platforms are used to refer to the Computer Supported Collaborative Learning (CSCL), simulations refer to the Technology Acceptance Model (TAM). The CSCL is a pedagogical approach where learning happens through social interaction using computer systems and users develop knowledge through communications and access to online resources. As a method for numeracy, by enhancing the numerical and logical abilities, e-learning platforms have been proven as useful systems (Amagir, Groot, Maassen van den Brink and Wilschut, 2018). On the other hand, TAM is an information system model based on the users' abilities to embrace and utilize tech-systems. Here, the learning process is facilitated via learning by doing in real-life simulated contexts (Ceschi, Dorofeeva, and Sartori, 2014). Evidence from research shows that the use of simulations is effective to improve financial decision-making (Harter and Harter, 2010; Jones and Chang, 2014).

According to the need for numerical literacy, we devised two training procedures based on the CSCL and TAM paradigms, i.e. using an e-learning platform and a simulation to evaluate their effectiveness. We focused on the incidence of behavioral-finance biases as the core evaluation for assessing numeracy among participants after the trainings. The present paper reports the preliminary results of our experimental exploration of the effectiveness of such methods. After briefly presenting the theoretical background of the technological methods, the method used, and the results of the examinations are present. In the last section, we discuss the results and the limitations of the study by providing indications for further examinations.

\section{The present contribution}

Considering the call for numerical abilities, we wanted to explore the effectiveness of technological methods for reducing behavioral-finance bias incidence based on the two main theoretical frameworks aforementioned. Referring to the CSCL paradigm, we proposed an e-learning system, Moodle (Moodle.org, 2018), in which participants were instructed to math and numerical principles as core abilities for financial decision-making (Wolla, 2017). Additionally, we devised a simulation training - TAM-based, the game-based training, Börse (Planspiel-Boerse, 2018). Through the learning-by-doing paradigm, participants were expected to show an increase their numerical abilities (Dal Santo and Martelli, 2015; Harter and Harter, 2010). After a brief presentation on financial decision-making, participants in the game-based training condition had to invest a virtual capital to be increased in the following ten weeks. To assess their performance, we selected five cognitive errors measures for evaluating the incidence of behavioral-finance biases (DeLong, \& Magin, 2009). We examined the effectiveness of both training methods comparing the two intervention groups and a control group. Our objective was to explore the effectiveness of the two technological tools for reducing behavioral-finance biases.

\subsection{Method}

Participants were recruited at the Department of Human Sciences, Verona University and they were randomly assigned to one of the three groups, two experimental groups and one control group. Each of them took part in the survey where we measured their level of behavioral-financial biases incidence. Eight hundred students were involved, with 22 years of median age $(S D=7.96$; range 19-59; 69\% female). $19.9 \%(N=159)$ of the participants attended the game-based training, $21.3 \%(N=170)$ the Moodle course while the rest of them $58.8 \%(N=471)$ composed the control group. Participation was anonymous. Self-report measures of financial-biases were used in a randomized system. During the e-learning intervention, participants were left to access to materials for studying, and search, and retrieve information from online databases. We presented them course materials in different forms and we mainly focused on mathematical and numerical concepts for enhancing numerical deals comprehension. The other group was involved in the simulation training, a Stock Market Game, i.e., a competition where participants had to invest a virtual capital trying to increase their amount of money or at least reduce the decrease. A brief presentation about stock market deals was given to leave students to only refer to their learning by gaming. To assess the decision-making process, five cognitive biases were selected as behavioral-Finance Biases for their occurrence during financial deals (DeLong and Magin, 2009; Thaler, 
1985). After all the trainings, participants completed the same questionnaire. Data have been analyzed with IBM SPSS statistics, version 21.1. After analyzing the reliability of the measures and the normal distributions within the samples, we used the one-way analysis of variance (one-way ANOVA) to explore whether there were significance differences between participants assigned to different groups in the level of the five cognitive biases selected.

\subsection{Results}

One-way ANOVA was conducted to compare the effect of technological methods on behavioral-finance biases incidence (E-learning platform vs Game-Based Training vs Control group). We found significant differences between groups. Participants in the Game-Based training group showed the lowest incidence of behavioral-financial biases, suggesting that such approach was more effective than the e-learning platform. In particular, the significant difference for cognitive task named money illusion, $\left(F(2,552)=2.61, p=.001, \eta^{2}=0.01\right)$ reveled a lower level for participants of the simulation $(M=47.73$, $S D=33.40)$ than other groups, as for the Zero Risk Bias, $F(2,670)=28.79, p=.001, \eta^{2}=0.08$, with a small average of incidence $(M=47.00, S D=30.85)$. On the other hand, the E-learning group reported a significantly lower incidence $(M=36.77, S D=16.67)$ of the Representation Bias $F(2,670)=4.88, p=.001$, $\eta^{2}=0.14$. There were no statistically significant differences between groups concerning other measures, rather than for Anchoring $\operatorname{Bias}(F(2,615)=19.36, p=.001)$ with a lower level for the game based group $(M=15.80, S D=10.46)$ than the other two groups. Regarding the last measures, mental account error, such behavioral finance bias resulted to be significantly higher in the control group and lower in the game-based group $\left(F(2,744)=19.61, p=.05, \eta^{2}=0.01\right)$. Although only four statistical differences are reported by the ANOVA, by the descriptive statistics, Game-Based training group revealed a lower incidence of behavioral-financial biases among the three groups. Participants of the real-life simulation showed better ability in solving economical and financial deals in comparison with the other two groups. On the other hand, the two groups didn't show significant differences reporting similar results in the incidence of cognitive errors.

\section{Discussion and limitations}

This study was motivated by the call for financial literacy and linked methods for improving individuals' performance in the increase of charges of numerical information (Lusardi, 2015). Accordingly, thanks to the current development of technological offers for training methods, coupled with the two major educational approaches (Dal Santo and Martelli, 2015; Król and Król, 2019; Willis, 2011), we devised two tech-interventions for reducing behavioral-finance biases. The assessment of financial literacy has been made by the evaluation of cognitive errors incidence. In fact, behavioral-finance biases occur when individuals have low level of numerical and financial literacy. Such complex measures have been considered and analyzed to verify the effectiveness of the tech-methods stressing the role of tech-training and formation as important for human beings. Our findings support that the existing evidence for game-based simulations training for financial biases. Although we did not find large significance among the tasks used, by the descriptive statistics, we can stress the effectiveness of the training. In fact, participants reported lower incidences among all the behavioral-finance biases except for the Anchoring Bias. On the other hand, the E-learning training did not reveal significant improvement. We believe that this training was not sufficiently rooted for helping participants to apply numerical and mathematical knowledge in financial tasks. Future studies may improve this training adding practical contents at the end of sessions.

Due to the fact that training, innovation, and new competences are highly recommended for facing with societal and organizational changes (Sartori, Costantini, Ceschi and Tommasi, 2018), as well as the recent the labor transformation with the massive presence of numerical information in digital shapes as a result of the so-called industry 4.0 (Tommasi, Franceschinis, Perini and Sartori, 2020), the present paper was additionally motivated to propose possible applied applications for training and education. Technological interventions can be used to enhance students' knowledge in school and academic context. Moreover, in organizational context, technological interventions can be used for life-long training to address not mastering individuals. Having noted the important implications of numerical literacy in today life, and the relevance of decision-making as key-competence to succeed in education and at work, this study hopes to add possible insights on how different kind of technology-based trainings can be effective to reduce cognitive biases. In particular, the present study aims to offer a possible exploration of such method in order to advance further examinations. 


\section{Conclusions}

The present study is not without limits. The sample composition and distribution limit our results to specific kind of populations giving few extended evidences. Forward empirical explorations and examinations may distribute participants equal groups. Additionally, although these findings support the notion that game-based learning is key to develop cognitive and operational competences, it should be noted, however, that we were unable to collect -pre-measures of participants' cognitive biases. Then, future studies may address our gaps devising more complex experimental design. Moreover, further examinations might address such examinations by involving examinations of individual math skills (Weller, Dieckmann, Tusler, Mertz, Burns \& Peters, 2013; Dal Santo and Martelli, 2015), as well as soft skills that might help in the development of specific knowledge (Tommasi, Franceschinis, Perini \& Tacconi, 2020). Technological methods for training are important offers of the increasing world of technologies. Coupled with learning theories (CSCL and TAM), we are able to make important insights into the learning process, and to build even more effective procedures for training. Our findings support the use of simulation for training intervention fostering numerical abilities for financial tasks. On the other hand, the results show our limits in E-learning training intervention devised. We suggest for future studies to add practical contents to improve, simultaneously, knowledge and financial abilities Overall, we hope these data and theoretical contributions will provide ideas for developing future evidence-based methods addressing the challenge of distant training and development.

\section{References}

Amagir, A., Groot, W., Maassen van den Brink, H., \& Wilschut, A. (2018). A review of financial-literacy education programs for children and adolescents. Citizenship, Social and Economics Education, $17(1), 56-80$.

Ceschi, A., Dorofeeva, K., \& Sartori, R. (2014). Studying teamwork and team climate by using a business simulation: How communication and innovation can improve group learning and decision-making performance. European Journal of Training and Development, 38(3), 211-230.

Dal Santo, A., \& Martelli, D. (2015). Increasing Financial Literacy through Simulations: The Case of the CFA Society Italy Fund Management Challenge. Journal of Financial Management, Markets and Institutions, 3(1), 69-100.

DeLong, J. B., \& Magin, K. (2009). The US equity return premium: past, present, and future. Journal of Economic Perspectives, 23(1), 193-208.

Fox, C. R., \& Tversky, A. (1995). Ambiguity aversion and comparative ignorance. The quarterly journal of economics, 110(3), 585-603.

Harter, C., \& Harter, J. F. (2010). Is financial literacy improved by participating in a stock market game. Journal for economic educators, 10(1), 21-32.

Jones, D. A., \& Chang, M. (2014). Pecunia-A Life Simulation Game for Finance Education. Research \& Practice in Technology Enhanced Learning, 9(1), 7-39.

Król, M., \& Król, M. (2019). Learning From Peers' Eye Movements in the Absence of Expert Guidance: A Proof of Concept Using Laboratory Stock Trading, Eye Tracking, and Machine Learning. Cognitive science, 43(2), 12-16.

Lusardi, A. (2015). Financial literacy: Do people know the ABCs of finance?. Public understanding of science, 24(3), 260-271.

Lusardi, A., and Mitchell, O.S. (2014) The economic importance of financial literacy: Theory and evidence. Journal of Economic Literature 52: 5-44.

MacGregor, D. G., Slovic, P., Dreman, D., \& Berry, M. (2000). Imagery, affect, and financial judgment. The Journal of Psychology and Financial Markets, 1(2), 104-110.

Moodle. International Society for Technology in Education. Retrieved March 27, 2019, from URL: https://moodle.org/

Olsen, R. A., \& Cox, C. M. (2001). The influence of gender on the perception and response to investment risk: The case of professional investors. The journal of psychology and financial markets, 2(1), 29-36.

Planspiel-Boerse, Retrieved March 27, 2019, from URL: http://www.sparkassen-schulservice.de and URL: http://www.planspiel- boerse.de

Rieger, M. O. (2012). Why do investors buy bad financial products? Probability misestimation and preferences in financial investment decision. Journal of Behavioral Finance, 13(2), 108-118. 
Sartori, R., Costantini, A., Ceschi, A., \& Tommasi, F. (2018). How Do You Manage Change in Organizations? Training, Development, Innovation, and Their Relationships. Frontiers in Psychology, 9, 313-324.

Shapira Z. (1995). Risk taking: A managerial perspective. New York: Russell Sage.

Shefrin, Hersh M. and Richard H. Thaler (1992), "Mental Accounting, Saving, and Self-Control," in Choice Over Time, George F. Loewenstein and John Elster, eds. New York: Russell Sage Foundation, 287-330.

Thaler, R. (1985). Mental accounting and consumer choice. Marketing science, 4(3), 199-214.

Tommasi, F., Franceschinis, I., Perini, M., \& Sartori, R. (2020). A systematic scoping review on skills variety for VET in the industry 4.0. In Proceedings of the International Conference on Education and New Developments (END) (pp. 474-476).

Tommasi, Francesco, Ioris Franceschinis, Marco Perini, and Giuseppe Tacconi. "Skilling for Tomorrow at School: A Training Project for IVET And Technical Students' soft Skills." In Education and New Developments (END) (pp. 100-104).

Waeneryd K.E. (2001). Stock market psychology: How people value and trade stocks. Northampton: Edward Elgar Publishing.

Weller, J. A., Dieckmann, N. F., Tusler, M., Mertz, C. K., Burns, W. J., \& Peters, E. (2013). Development and testing of an abbreviated numeracy scale: A Rasch analysis approach. Journal of Behavioral Decision Making, 26(2), 198-212.

Willis, L. E. (2011). The financial education fallacy. American Economic Review, 101(3), 429-34.

Wolla, S. (2017). Evaluating the effectiveness of an online module for increasing financial literacy. Social Studies Research and Practice, 12(2), 154-167. 